\title{
1. O primeiro Secretário-Geral da AULP (1986-2002)
}

\author{
Manuel J. Coelho da Silva
}

Secretário Geral da AULP (1986-2002)

\section{No início eram dezasseis}

Olhar o passado ajuda a perceber o presente e a projetar o futuro. É uma frase feita, eu sei, mas é também aquela que melhor traduz este revisitar da história da Associação das Universidades de Língua Portuguesa (AULP).

Quando um pequeno grupo de dirigentes, representando 16 instituições de ensino e investigação de nível superior, oriundos de cinco países de língua portuguesa ${ }^{1}$, se reuniram na cidade da Praia, em Cabo Verde e, em finais de novembro de $1986^{2}$, aprovaram os primeiros Estatutos e subscreveram a acta que formalizou a escolha do seu primeiro Presidente (António Simões Lopes, Reitor da Universidade Técnica de Lisboa), estava-se ainda longe de prever a importância que viria a assumir a Associação das Universidades de Língua Portuguesa (AULP).

De facto, as tensões ainda eram muitas e avançar para a criação de uma organização não governamental não era tarefa que se acreditasse vir a ser fácil.

\footnotetext{
1. Assinaram o compromisso constitutivo da AULP a 26 de Novembro de 1986 as seguintes instituições: Brasil - Universidade Federal do Maranhão (Reitor José Maria Cabral Marques); Universidade Federal do Espírito Santo (Reitor José António Abi-Zaid), Universidade Federal Fluminense (Reitor José Raymundo Martins Romêo), Universidade Católica de Pelotas (Reitor Paulo Brenner Soares), Universidade de Caxias do Sul (Reitor Abrelino Vicente Vazatta); Cabo-Verde - Escola de Formação de Professores do Ensino Secundário (Alberto da Mota Gomes), Escola Náutica do Mindelo (Hermes Évora), Instituto Amílcar Cabral (Luíza Ribeiro) e Instituto Nacional de Investigação e Desenvolvimento Agrário (Osvaldo Cruz); Guiné-Bissau - Instituto Nacional para o Desenvolvimento da Educação (Presidente José Vieira); Moçambique - Universidade Eduardo Mondlane (Reitor Rui Baltazar dos Santos Alves); Portugal - Universidade de Aveiro (Reitor (em exercício) Aristides Hall), Universidade de Coimbra (Vice-Reitora Maria Helena Rocha Pereira), Universidade de Lisboa (Reitor Virgílio Meira Soares), Universidade Técnica de Lisboa (Reitor (em exercício) António Simões Lopes) e Instituto de Cultura e Língua Portuguesa (Presidente Fernando Cristóvão) e o Secretário do Conselho de Reitores das Universidades Portuguesas (Manuel Joaquim Coelho da Silva).
}

2. Importa lembrar, para a história da AULP, algumas personalidades e factos que, provavelmente, só eu conheço: a Professora Maria Helena Rocha Pereira, vice-reitora da Universidade de Coimbra, é a autora da divisa da AULP: "Ex unitate vis"; o pintor José Manuel Ralha foi quem criou o primeiro emblema da AULP; os membros do governo português Alberto Ralha, João de Deus Pinheiro, Roberto Carneiro, Diamantino Durão, Marçal Grilo, Arantes de Oliveira e Sucena Paiva foram absolutamente fundamentais no financiamento da instituição; o embaixador José Augusto Seabra foi quem promoveu o reconhecimento da AULP junto da UNESCO; o presidente da Câmara Municipal de Lisboa, João Soares, cedeu as instalações onde hoje é a sede internacional da Associação; e o Governador de Macau, General Rocha Vieira atribuiu à AULP os meios financeiros para que a AULP se pudesse instalar em Lisboa. 
Honra seja feita a esse punhado de sonhadores que acreditavam firmemente que a educação e a língua que nos unia seria o fermento aglutinador de vontades e o cimento que nos ligaria nessa nova plataforma de afirmação da lusofonia no mundo, que a AULP representa.

Preparar, analisar, discutir e aprovar os estatutos de uma organização internacional não é, não foi!, tarefa fácil. Porém, todos sentiam, posso confirmá-lo porque o vivi pessoalmente, que o que nos unia era bem mais relevante do que o que nos separava.

Quando na tarde de 26 de novembro de 1986, sentados à volta de uma mesa e recorrendo a meios e instrumentos de trabalho muito longe dos atuais, se conseguiu, finalmente, aprovar os Estatutos e proceder à eleição do primeiro presidente (e também do primeiro Secretário Geral) da Associação das Universidades de Língua Portuguesa, um frémito de emoção e solenidade, aliado à consciência de que se estava a viver um momento histórico, perpassou por todos os presentes.

Como é natural, para chegar até aqui, muito esforço e perseverança tinha sido suporte da ideia de lançar o ambicioso projeto de criação de uma organização não governamental que criasse dinâmicas de entre-ajuda a nível do ensino superior dos "novos e velhos" países de língua portuguesa, avultando o trabalho de Eduardo Romano de Arantes e Oliveira, reitor eleito da Universidade Técnica de Lisboa (1977-1987), mais tarde nomeado Secretário de Estado da Investigação Científica do Governo de Portugal (8 de novembro de 1985 a 18 de agosto de 1987) e que foi neste domínio perfeitamente visionário. Conseguiu reunir vontades dos Conselhos de Reitores das Universidades Brasileiras (CRUB) e Portuguesas (CRUP), do Ministro da Educação de Cabo Verde (Corsino Tolentino) e do Reitor da Universidade Eduardo Mondlane (e ex-Ministro das Finanças do Governo de Moçambique), Rui Baltazar dos Santos Alves.

Ao grupo inicial juntou-se a única instituição da Guiné-Bissau de formação docente, representada pelo José Vieira.

Aos dois juristas presentes (Lucinda Cruz, Moçambique, e eu próprio, enquanto Secretário do Conselho de Reitores das Universidades Portuguesas) coube a tarefa de criar as bases jurídicas e técnicas que, pela cumplicidade que traduziam, nunca foram objeto de qualquer controvérsia.

A António Simões Lopes, reitor em exercício da UTL, que entretanto substituíra o reitor eleito Arantes e Oliveira enquanto este desempenhava funções governamentais, coube, por mérito próprio, a honra de assumir a primeira presidência da AULP e a mim o lugar de Secretário-Geral que acabei por desempenhar durante dezasseis anos.

O professor António Simões Lopes foi a pedra angular da credibilidade da novel Instituição, dando continuidade com enorme entusiasmo e proficiência ao projeto da AULP, promovendo de forma segura e sem desfalecimento as tarefas institucionais, ultrapassando diplomaticamente todas as barreiras de desconfiança e indiferença. 
REUNIAO IWTERNACIONAL CONSTIIUTIVA DA ASSOCIACRO DAS UNIVERSIDADES

QE LINGUA PORTUGUESA

ACTA DE ELEICYAO

Aos 26 de Novembro de 1986, pelas 17H00, nos termos do artigo 45 do Estatuto da Associaçâo das Universidades de Lingua Portuguesa, os participantes à reuniâo procederam à eleiçâo do Presidente da Associaçâo. As Instituiçoês de Ensino e Investigaçâo de nivel superior da Republica de Cabo Verde propberam a candidatura da Universidade Técnica de Lisboa aqui representada pelo Professor Doutor SIMOES LOPES para Presidente da Associaçâo. Esta proposta foi apoiada sucessivamente pelas Universidades e Instituiçoês de Ensino Superior do Brasil, Guiné-Bissau, Moçambique e Portugal.

Assim, foi eleita a Universidade Técnica de Lisboa para Presidente da Associaçâo das Universidades de Lingua Portuguesa por aclamaçâo,

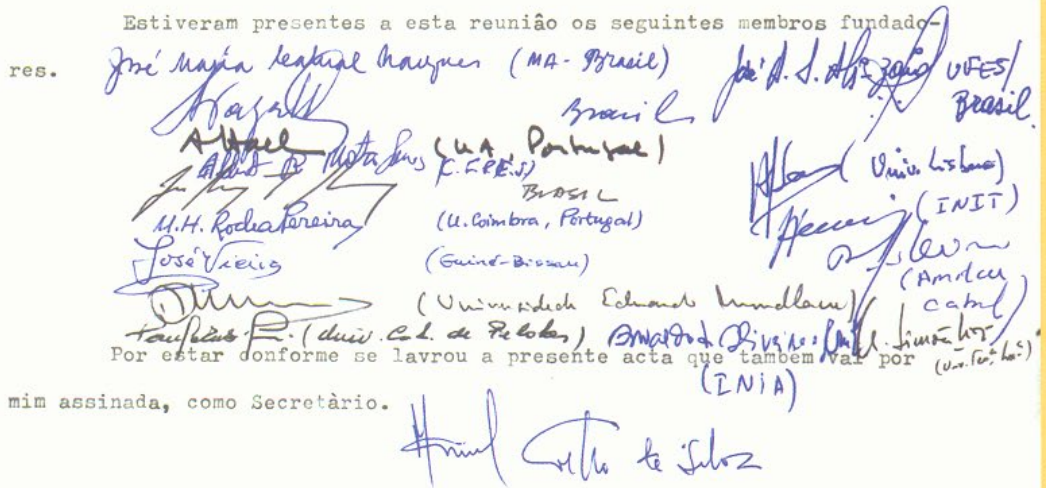

\section{Os quatro pilares da ação da AULP:}

- Promoção da Cooperação e Intercâmbios

Os objetivos da AULP eram simples e claros, mas muito desafiadores, no contexto que então se vivia e tendo em conta a escassez de recursos financeiros. Para além de visar promover a cooperação entre as instituições de ensino e investigação superior dos países de língua portuguesa, a Associação procurava desenvolver a sua ação, concorrendo para salvaguardar a herança comum que é a 
língua portuguesa, reconhecendo que para isso havia necessidade do apoio e do contributo de todos.

Promovendo projetos de investigação científica e tecnológica em conjunto nas áreas ou temas de interesse dos associados, procurava-se ainda estimular o conhecimento da realidade e o desenvolvimento de cada um dos países, incrementando o intercâmbio de docentes, investigadores, estudantes e pessoal administrativo, com vista à participação em ações de natureza pedagógica, científica, cultural e administrativa que se realizassem em cada um dos membros da Associação; fomentando a circulação de informação científica, técnica, pedagógica e cultural, o intercâmbio de revistas e publicações científicas, bem como a edição conjunta e a divulgação de trabalhos científicos; estimulando a elaboração de acordos bilaterais e multilaterais entre os membros da Associação em todos os domínios do seu interesse e particularmente no âmbito das equivalências de habilitações literárias e graus científicos e académicos, conferidos pelas instituições associadas; apoiando também a reflexão sobre o papel da educação superior, suas estruturas e meios de ação no mundo atual e particularmente nas nossas sociedades, numa ação de apoiar a criação de estruturas do ensino e de investigação que facilitassem a realização dos fins da Associação.

Não era coisa pouca! Paulatinamente, a AULP foi disseminando a sua ação e logo na primeira assembleia geral, que teve lugar na Universidade de Évora (Portugal), ainda em Novembro de 1986, alargou-se o número de associados, tendo sido deliberado criar uma Carta Informativa (cujo primeiro número saiu a 1 de outubro de 1987), instrumento indispensável de comunicação entre associados dispersos pelos cinco continentes. Esta ideia foi reforçada na $2^{\text {a }}$ Assembleia Geral, no mês de Abril de 1987, em Maputo (Moçambique).

A cooperação efetiva entre instituições não parou mais. A Universidade de Aveiro, logo no primeiro ano de vida da AULP, conseguiu apoiar o Instituto Nacional para o Desenvolvimento da Educação (Guiné-Bissau) na formação de professores, tendo a Direção Geral da Cooperação Portuguesa oferecido então 20 bolsas de estudo para o efeito.

De igual modo, a cooperação científica começou a assumir um crescente interesse entre as instituições membro. Um ano depois, a Universidade Agostinho Neto e Instituto Politécnico de São Tomé e Príncipe pedem a sua adesão, a que se seguem instituições de Macau e Timor.

\section{- Os encontros temáticos}

A AULP começou a marcar a agenda das instituições, promovendo encontros científicos. O I Encontro da AULP, (já se vai no XXVI), teve lugar dois anos após a sua criação e decorreu em Lisboa, nos dias 28, 29 e 30 de novembro de 1988, sob o tema "Os Problemas da Língua e o Conhecimento das Culturas" e contou 
com a participação de representantes de Portugal, Brasil, Cabo Verde, Guiné, São Tomé e Príncipe e Moçambique, envolvendo mais de 70 docentes.

Considerando a importância deste Encontro, para o debate de problemas relacionados com o ensino, divulgação e preservação da língua portuguesa, bem como para o aprofundar de questões ligadas ao conhecimento das culturas, entendeu-se por bem lançar uma Revista que passou a designar-se Revista Internacional de Língua Portuguesa (RILP). O foco do primeiro número da RILP foi constituído por todas as comunicações que foram entregues pelos participantes no I Encontro.

VI Encontro AULP - 1996 (Lisboa, Portugal)
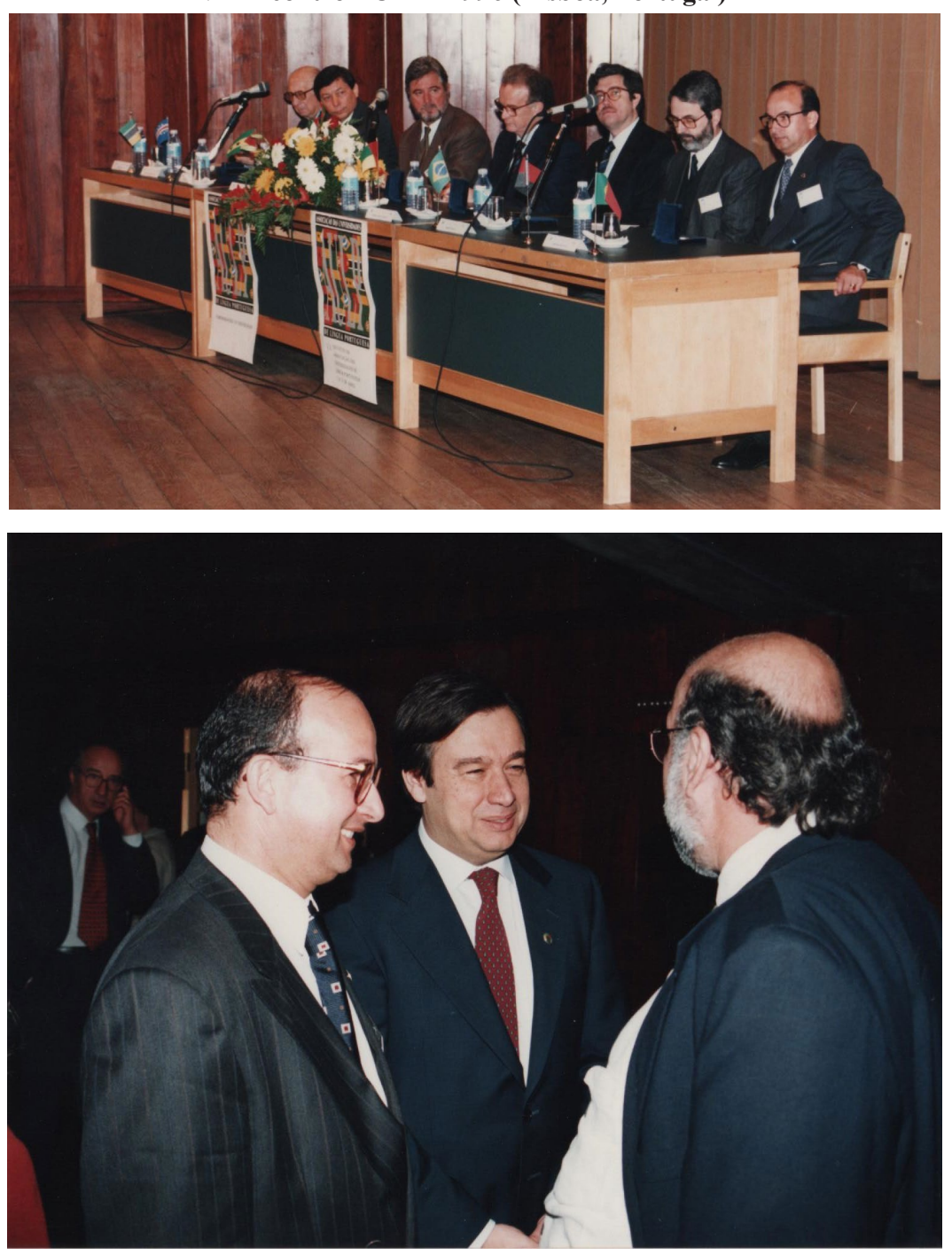

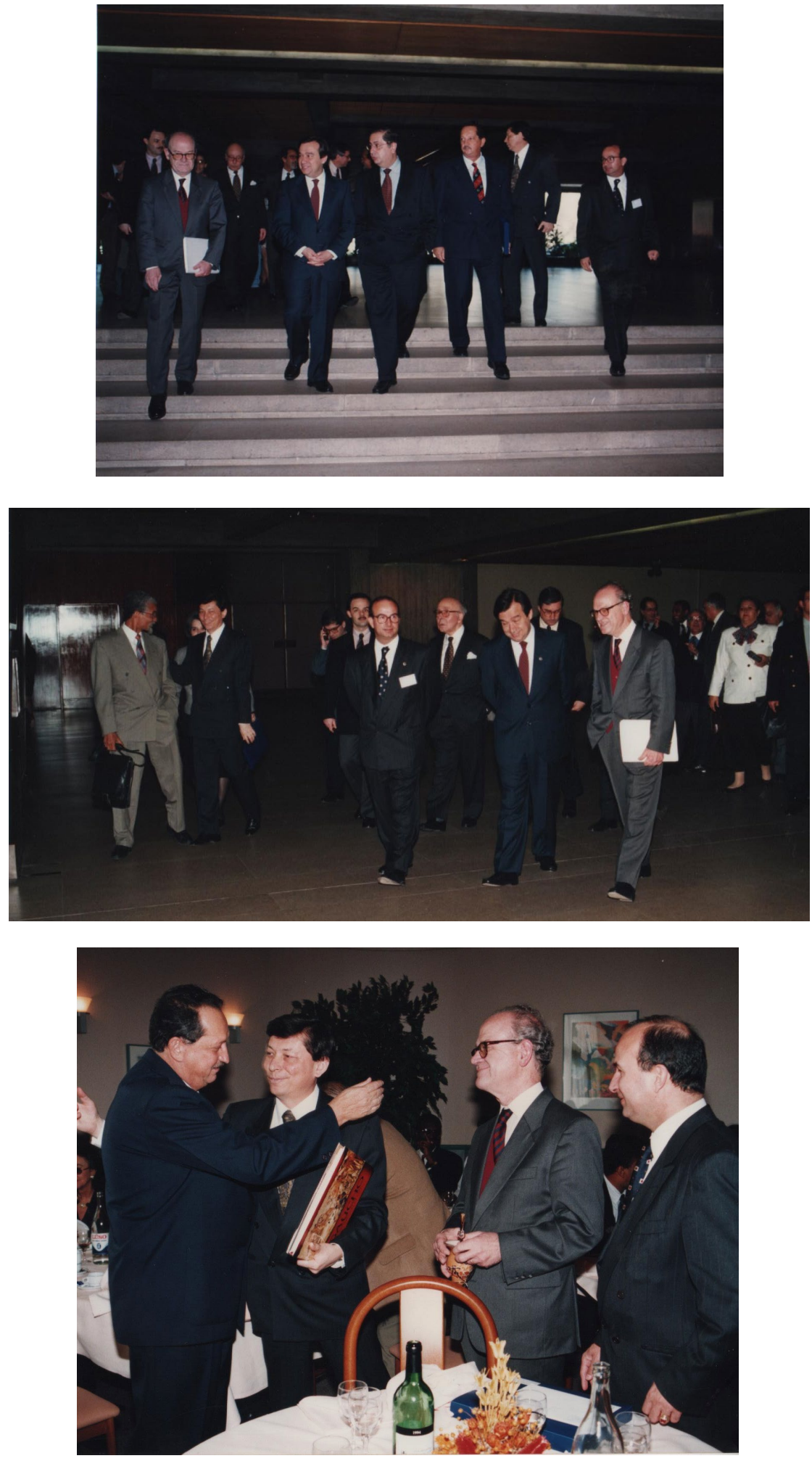


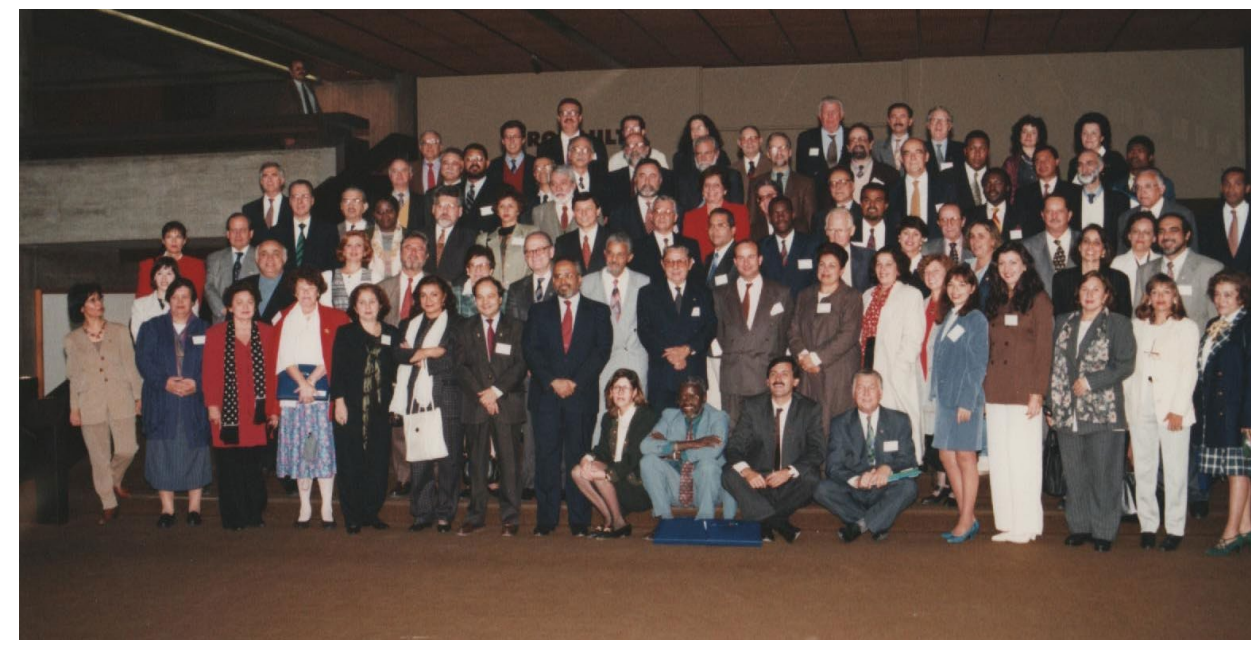

VII Encontro AULP - 1997 (Rio de Janeiro, Brasil)

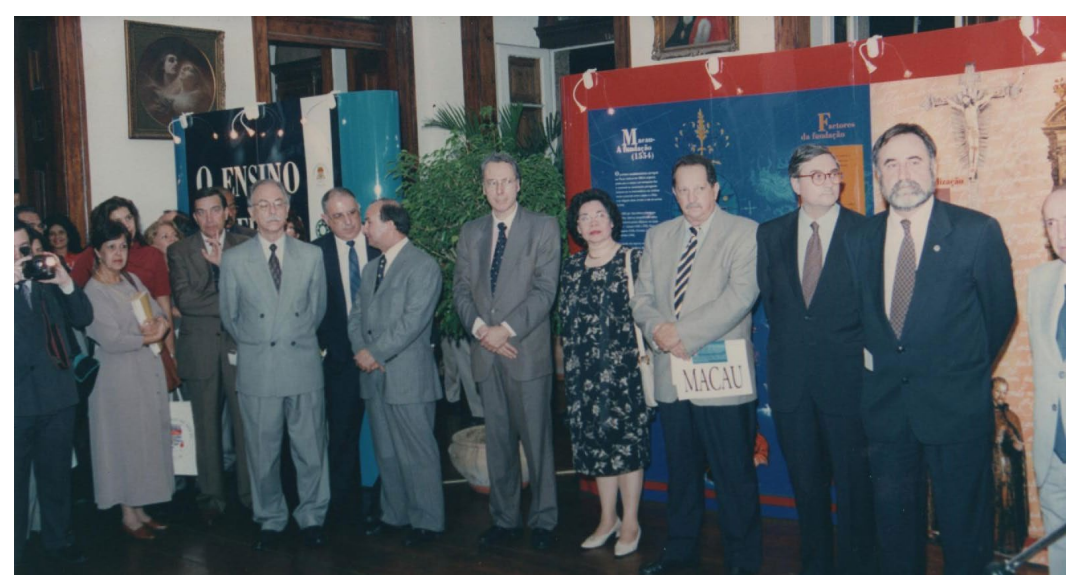

VIII Encontro AULP - 1998 (Macau - RAEM, China)

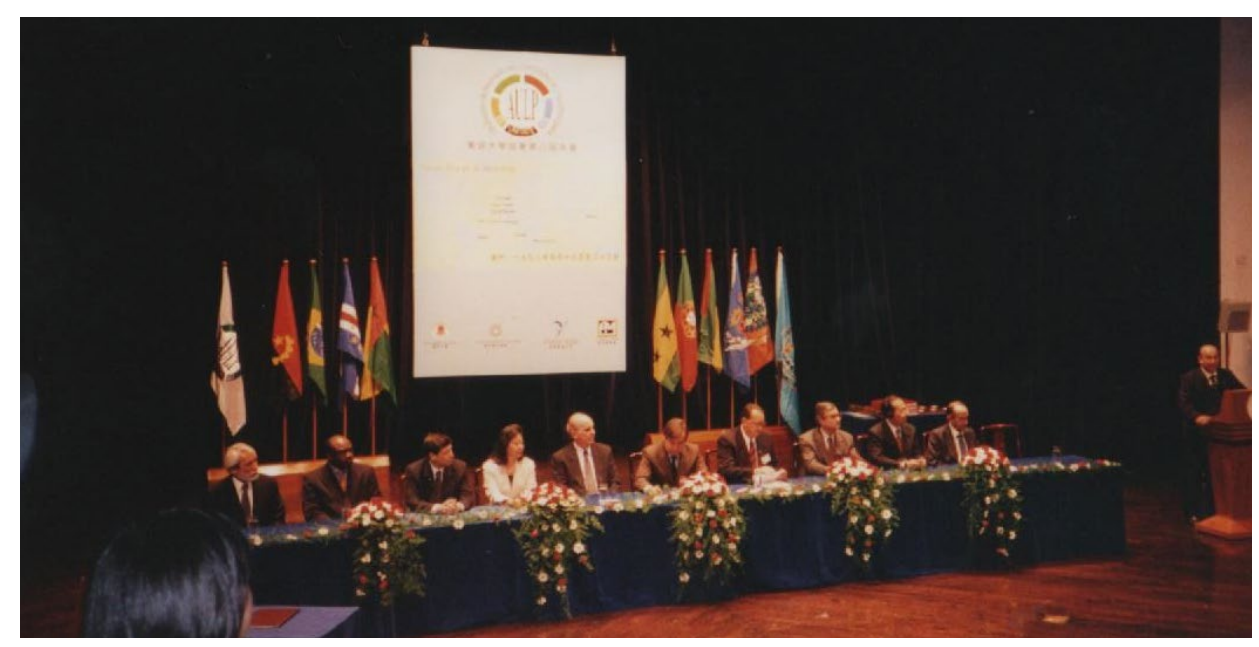


IX Encontro AULP - 1999 (Maputo, Moçambique)

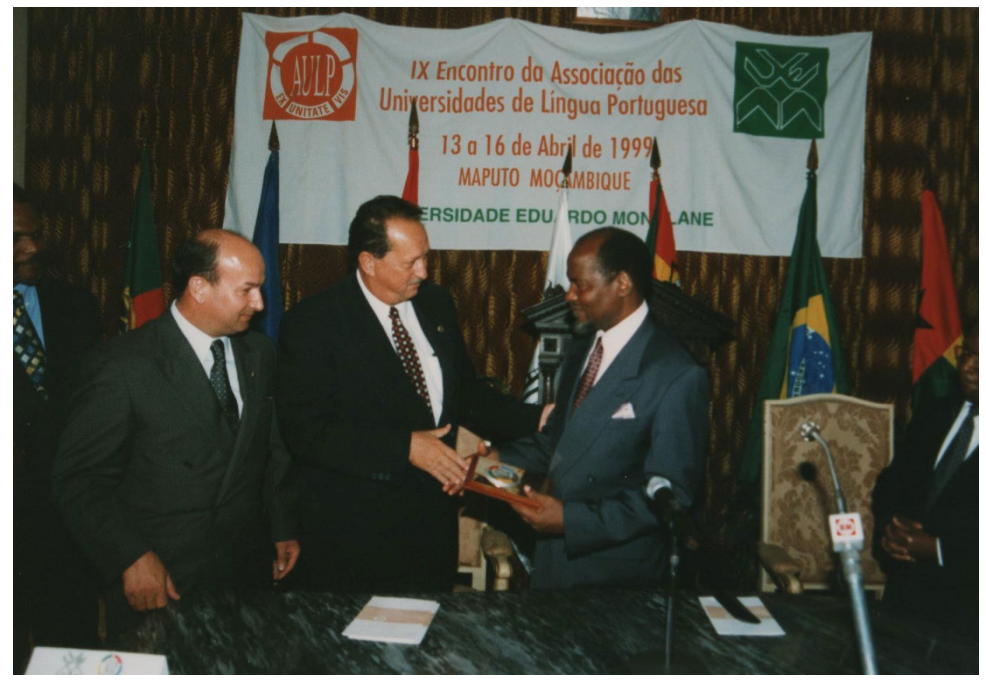

XII Encontro AULP - 2002 (Luanda, Angola)
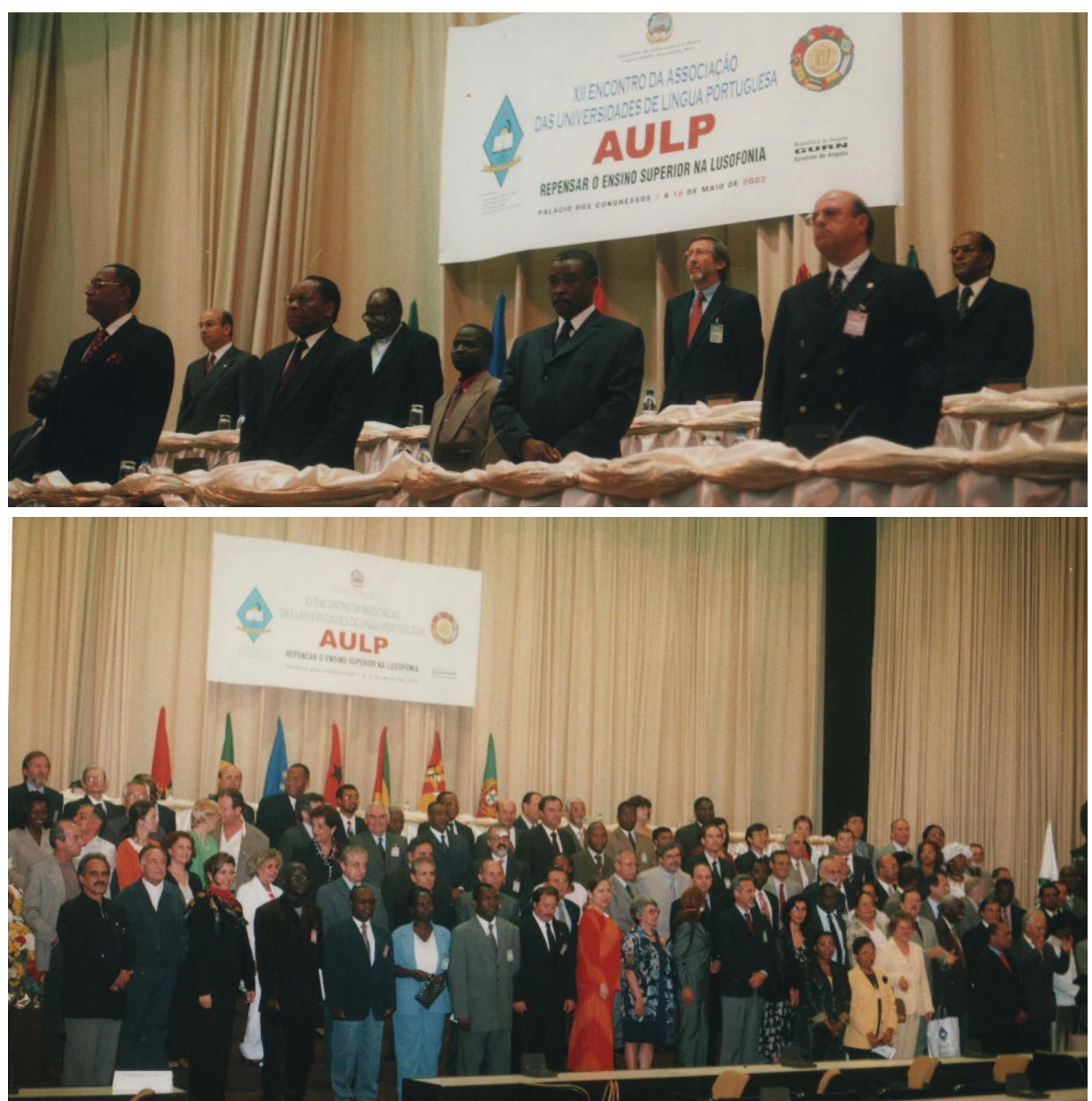


\section{- A Revista Internacional de Língua Portuguesa (RILP)}

Tratando-se de uma revista internacional, que abrangia as diversas variantes do português, a que correspondiam algumas diferenças ortográficas, o Conselho Científico da Revista decidiu manter na época a ortografia original de cada artigo.

Como primeira diretora da RILP o Conselho de Administração da AULP escolheu a professora Maria Helena Mira Mateus, docente da Universidade de Lisboa, tendo-lhe sucedido na direção, mais tarde, o professor José Augusto Seabra, da Universidade do Porto.

Com a Revista pretendia-se, para lá do objetivo fundamental de criar um espaço de discussão das questões linguísticas, que fosse (seja) um lugar privilegiado em que se divulgassem instrumentos pedagógicos que reforçassem e favorecessem o ensino e a aprendizagem do português e ainda que esta se assumisse como uma forma de indispensável discussão científica para um mais e melhor efetivo conhecimento da diversidade e unidade da língua portuguesa.

O projeto RILP procurou dessa forma ao longo dos anos abordar o processo de ensino-aprendizagem da língua portuguesa (materna ou segunda) e do seu uso como veículo sociocultural, numa perspetiva de investigação em áreas linguísticas, históricas, literárias e culturais.

A RILP assumiu-se sempre como um precioso instrumento de divulgação de resultados de investigação e veículo de intercomunicação entre as instituições ou grupos de trabalho e os indivíduos, sempre que relacionados com os interesses das diferentes partes que integram a Associação das Universidades de Língua Portuguesa.

Estes objetivos, ontem como hoje, mantêm legitimidade e interesse e fazem augurar muitos anos de vida para este pilar de comunicação da AULP.

\section{- Programa de bolsas de estudo para formação avançada}

A necessidade de apoio à criação de uma massa crítica, absolutamente indispensável para o crescimento e desenvolvimento das Instituições dos novos Países de Língua Portuguesa, fez com que a AULP lançasse um significativo Programa de Bolsas de Estudo para Formação Avançada - Doutoramento que, ao tempo, constituiu uma verdadeira pedrada no charco. Vários foram os docentes que ao abrigo desse programa puderam concluir os seus doutoramentos.

O envolvimento das diversas Instituições associadas, a que se juntou um significativo apoio financeiro do Governo Português, assumiu natureza estratégica e traduziu-se numa das mais importantes atividades da AULP, não só pelo que significava de aproximação entre países, como também pela projeção da AULP nos diversos grupos de docentes. 


\section{Em síntese:}

Trinta anos não será muito na vida de uma instituição, mas se nos lembrarmos do momento e das circunstâncias em que nasceu, cresceu e se consolidou, a Associação das Universidades de Língua Portuguesa, temos que expressar com regozijo o êxito que ela representou, e representa, como símbolo de união entre Povos que, preservando as suas culturas, souberam aplainar diferenças, valorizando o seu património comum que é a Língua.

Antes mesmo da constituição (1996) da Comunidade dos Países de Língua Portuguesa (CPLP) a AULP já tinha trilhado um longo caminho de comunhão de boas vontades, expresso numa participação ativa na ideia de criação do Instituto Internacional de Língua Portuguesa (IILP) e no desenvolvimento de múltiplas ações de cooperação.

De um universo de 16 subscritores, reunidos na Cidade da Praia, a AULP tinha crescido em 2002, no momento em que cessaram as minhas funções de Secretário-Geral, para 115 membros titulares e 9 membros associados.

Convenhamos, não foi coisa pouca! 